\title{
The outstanding academic achievements of Prof. Gennady E. Zaikov
}

\author{
Victor M.M. Lobo* \\ Department of Chemistry, University of Coimbra, 3004-535 Coimbra, Portugal
}

Prof. Zaikov (Figure 1) was born in Omsk, Siberia (then USSR) where he graduated from the local primary, middle, and high school, and on January 7 , 2015 will be his 80th birthday. He also graduated from a musical professional school where he studied violin and pianoforte. His parents Efrem and Matrena encouraged him to continue his education by following in the footsteps of his mother - a chemistry teacher in the High School and Omsk's Medical Institute (his father was a mathematician and land-surveyor). Therefore, in 1952 Gennady moved to Moscow where he entered the Moscow State University (MSU), and he graduated with a chemistry degree in December 1957. His bachelor's degree dealt with the problem of separating ${ }^{6} \mathrm{Li}$ and ${ }^{7} \mathrm{Li}$ isotopes. After this, he joined the Institute of Chemical Physics (ICP) in Moscow in February 1958. In 1996 this Institute was split into two parts: N. N. Semenov Institute of Chemical Physics (ICP) and N. M. Emanuel Institute of Biochemical Physics. Presently, Prof. G. E. Zaikov is working at the N. M. Emanuel Institute of Biochemical Physics (IBP), and therefore he always worked in the same place.

Gennady was originally invited to ICP by Professor Nikolai Markovich Emanuel. Under his guidance, defended in 1963 his Ph.D. thesis entitled "Comparison of the Kinetics and Mechanism of Oxidation of the Organic Compounds in Gaseous and Liquid Phases" in 1963. These results were the foundation of some industrial applications. A plant floor in Moscow petrochemical plant (Kapotnya district) was built for the production of 10000 tons/year of acetic acid and 5000 tons/year of methylethylketone from the oxidation of n-butane in liquid phase in critical conditions $\left(50 \mathrm{~atm}, 150{ }^{\circ} \mathrm{C}\right)$. The main contributors of this plant floor were N.M. Emanuel, E.A. Blumberg, Z.K. Maizus, M.G. Bulygin, E.B. Chizhov and G.E. Zaikov. In 1968, he defended a Doctor of Science thesis entitled "The Role of Media in Radical-Chain Oxidation Reactions". In 1970 he became a full professor.

In 1966, Gennady became involved with polymer science. N. M. Emanuel charged him with the organization of research on problems associated with aging and stabilization of polymers, and, later, with the combustion of polymeric materials. In the 1970s, there were about 1000 scientists (about 50 research centers) in the U.S.S.R. working on these problems, including 200 scientists from

\footnotetext{
* Corresponding author. E-mail address: vlobo@ci.uc.pt
} 
ICP under Zaikov's leadership. The research was conducted on all aspects of these polymer problems, e.g., thermal degradation, oxidation, ozonolysis, photodegradation and radiation degradation, hydrolysis, biodegradation, mechanical degradation, pyrolysis, and flammability. Scientists from synthetic laboratories of this division (Prof. V.V. Ershov, E.G. Rozantsev, K.M. Dyumaev) prepared several very important and original stabilizers for polymers and organized the production of these stabilizers.

After "perestroika", and dissolution of the U.S.S.R. in 1991, the new Russian government decreased significantly the financial support for science. So, G. E. Zaikov has now with him in the N. M. Emanuel Institute only 15 coworkers (instead of 200 in 1970-1980s).

He compensated the decreasing of scientists in his Institute by increasing the cooperation with other research centers in Russia and other countries: 20 Research centers in USA and EU countries (including the Department of Chemistry of the University of Coimbra, Portugal), 8 centers in CIS-cooperation and 20 research groups inside Russia.

Zaikov left his position as head of laboratory in September 2007, but he became head of the Polymer Division (PD) in IBP, including 3 laboratories (about 50 scientists).

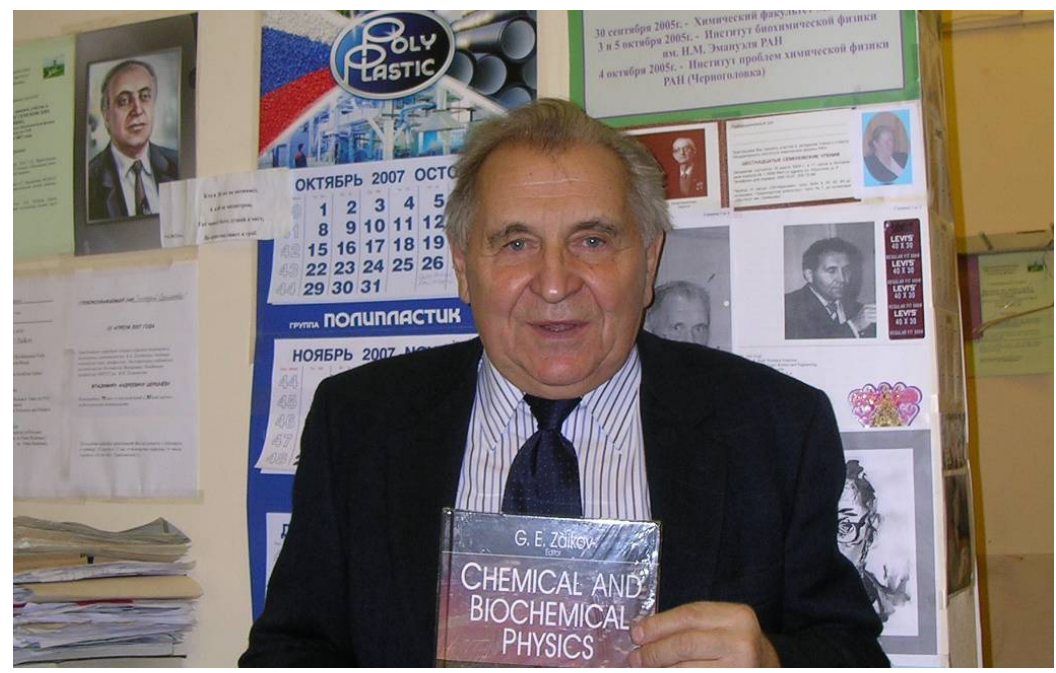

Figure 1. Professor G.E. Zaikov (November, 9 2007) with his new book "Chemical and Biochemical Physics" (Nova Science Publishers, New York).

Prof. Zaikov is an outstanding scientist with expertise in wide areas of chemistry: chemical and biological kinetics, chemistry and physics of polymers, history of chemistry, biochemistry. In addition to his position at the N. M. Emanuel Institute, he is a lecturer at the Moscow State Academy of Fine Chemical Technology and he is researcher at Volzhsk Branch of Volgograd State Technological University. He taught his students from his own books: "Degradation and Stabilization of Polymers", "Physical Methods in Chemistry", and "Acid Rains and Environmental Problems". G. E. Zaikov has written about 4000 original articles, 400 monographs (100 in Russian and 300 in English), and 350 chapters in 80 volumes. His index of scientific activity (Chirsch) is equal to 
30 units. It is apparent from this work that he has made valuable contributions to the theory and practice of polymers - aging and development of new stabilizers for polymers, organization of their industrial production, life-time predictions for use and storage, and the mechanisms of oxidation, ozonolysis, hydrolysis, biodegradation, and decreasing of polymer flammability. New methods of polymer modification using the processes of degradation were introduced into practice by Zaikov. These methods allow the production of new polymeric materials with improved properties. Recently, he became very active in the field of semiconductors and electroconductive polymers, polymer blends, and polymer composites, including nanocomposites.

Prof. Zaikov is a member of editorial boards of a significant number of journals published in Russia, Poland, Bulgaria, the U.S.A. and England

$\mathrm{He}$ is a member of the Academy of Creation (San Diego, USA - Moscow, Russia), International Academy of Sciences (Munich, Germany), American Chemical Society, Plastic Engineering Society (USA) and Royal Chemical Society (UK).

In the former Soviet Union (after academician N. M. Emanuel's death), he headed the team dealing with the problem of polymers aging in the U.S.S.R. and in the Eastern European countries in cooperation with the Soviet Academy of Sciences. Presently, he is head of Division, member of the directorium, and deputy of department of the N. M. Emanuel Institute of Biochemical Physics, Russian Academy of Sciences, Professor of Polymer Chemistry in Moscow State Academy of Fine Chemical Technology, Professor of Polymer Chemistry in Volzhsk Branch of Volgograd State Technical University. His field of interests includes Chemical Physics, Chemical Kinetics, Flammability, Degradation and Stabilization of Polymers, Diffusion, Polymer Materials, Kinetics in Biology, History of Chemistry, Jokes, etc.

Prof. Zaikov had a sister, Zinaida E. Zaikova, who was a teacher of mathematics in high school (she died some years ago). Another two of his sisters (Klara and Inna) died during the Stalin collectivization period at the end of the 1920s from starvation. Zaikov's wife, Marina Izrailevna Artsis is a member of the N. M. Emanuel Institute of Biochemical Physics and is a Ph.D. in Chemistry. His son, Vadim G. Zaikov, is a Senior Research Chemist at the Avery Dennison Co. (Ohio, USA). He received a Ph.D. in Chemistry in the USSR, and later received another Ph.D. from the College of William and Mary (Williamsburg, VA), working in the laboratory of Prof. William H. Starnes. Prof. Zaikov's granddaughter Alexandra (23 years old) is a student in Chicago (USA), and his grandson Denis (14 years old) is a schoolboy in Perry, Ohio (USA).

On his 80th anniversary, G. E. Zaikov is in the prime of his life. Although support for scientists and research is now at a low point for many in Russia, he is hopeful that, for the sake of his country and its future, this situation will improve in the future.

The practice of good science still exists in Russia and Prof. Zaikov has always been and still is a significant contributor. We wish him a most happy birthday. 